\title{
Influência do etanol como cosubstrato na biorremediação de água contaminada com formulação comercial à base de glifosato
}

\author{
Influence of ethanol as a co-substrate on bioremediation of water \\ contaminated with glyphosate-based comercial formulation
}

\author{
Renata Medici Frayne Cuba** ${ }^{10}$, Túlio Salatiel Cintra² ${ }^{(0}$, \\ Débora Cristina Chaves Paiva' ${ }^{\circledR}$, Francisco Javier Cuba Terán' ${ }^{\circledR}$
}

口-

\begin{abstract}
RESUMO
O presente trabalho objetivou avaliar a eficiência e a cinética de degradação de formulação comercial à base de glifosato em amostras de água, previamente contaminadas, via processo aeróbio, utilizando etanol como cosubstrato no processo. Utilizou-se um reator aeróbio com capacidade volumétrica de $1 \mathrm{~L}$, operado em sistema de batelada sequencial com ciclos de 24 horas e biomassa em suspensão. Foram testadas quatro fases sob diferentes condições nutricionais: 1 sem a presença do etanol e outras 3 com relação etanol:glifosato de 7,8:1, 27,5:1 e 18,3:1. Quando o sistema operou sem a presença de etanol, a eficiência de remoção do glifosato foi de 18\%, a qual aumentou para $78 \%$ ao se adicionar etanol na relação 7,8:1. No entanto, ao aumentar a concentração de etanol nas demais fases, não foram observadas melhoras na eficiência de remoção devido, provavelmente, à preferência dos organismos pelo uso do etanol como fonte de carbono em relação ao glifosato. Com relação aos ensaios cinéticos, os resultados foram ajustados ao modelo de degradação de pseudoprimeira ordem, considerando o residual de glifosato. A fase 3, com relação etanol:glifosato 27,5:1, foi a que apresentou maior valor da constante cinética aparente, $\mathrm{k}=0,01746 \cdot \mathrm{min}^{-1}$. Os resultados obtidos neste estudo indicam que a utilização de etanol como cosubstrato pode ser uma alternativa para a descontaminação de águas contaminadas com glifosato.
\end{abstract}

Palavras-chave: glifosato; cosubstrato; tratamento aeróbio.

\begin{abstract}
This study aimed to evaluate the efficiency and degradation kinetics of commercial glyphosate formulation in previously contaminated water samples via aerobic process using ethanol as a co-substrate. An aerobic reactor with $1 \mathrm{~L}$ volumetric capacity operated in sequential batch system with 24-hour cycles and suspended biomass was used. Four different nutritional conditions were tested: one with no ethanol addition; and three others with ethanol: glyphosate ratios of 7.8:1, 27.5:1 and 18.3:1. Operating with no ethanol addition, the efficiency of glyphosate removal was $18 \%$ and increased to $78 \%$ when ethanol was added to the system in a 7.8:1 ratio. However, when glyphosate concentration was further increased in the next phases, it did not result in higher removal efficiency, probably due to the preference of organisms for ethanol use as a carbon source over glyphosate. The results of the kinetic tests adjusted to first-order degradation models considering residual glyphosate. Phase 3 with 27.5:1 ethanol/glyphosate ratio showed the highest apparent kinetic constant value, $k=0.01746$. The results of this study suggest that using ethanol as a co-substrate can be an alternative for decontamination of glyphosate contaminated waters.
\end{abstract}

Keywords: glyphosate; co-substrate; aerobic treatment.

\section{INTRODUÇÃO}

O aumento na produção de alimentos em larga escala para atender à demanda populacional reflete, diretamente, na produção e utilização de agroquímicos, entre os quais o glifosato ( $\mathrm{N}$-(fosfonometil) glicina) — um herbicida de amplo espectro, não seletivo, sistêmico e pós-emergente, com elevada eficiência na eliminação de ervas daninhas (AMARANTE
JUNIOR, et al., 2002) - tem sido, desde 2001, o ingrediente ativo mais utilizado, com valores de produção mundial entre 122 e 131 mil toneladas do produto em 2012 (USEPA, 2017).

Apesar do elevado consumo, as concentrações de glifosato no ambiente ainda são detectadas abaixo dos níveis atuais considerados seguros para a saúde humana e dos ecossistemas (BATTAGLIN et al., 
2014; WILLIAMS; KROES; MUNRO, 2000). No entanto, esse entendimento tem gerado controvérsias, pois estudos recentes demonstram que, nessas concentrações, tanto o glifosato quanto suas formulações comerciais podem afetar não somente as plantas alvo, mas também organismos terrestres e aquáticos (SUN et al., 2013; MUÑOZ; VELÁSQUEZ; BAUTISTA, 2015; BONIFÁCIO et al., 2016).

No Brasil, a legislação limita a concentração desse composto nos recursos hídricos em $65 \mu \mathrm{g} . \mathrm{L}^{-1}$ para rios classes 1 e 2 e $280 \mu \mathrm{g} . \mathrm{L}^{-1}$ para os classe 3 (BRASIL, 2005). No entanto, o processo de produção do glifosato gera efluentes que podem apresentar concentrações da ordem de 20 g.L L $^{-1}$ do seu sal (XIE; LIU; XU, 2010), motivo pelo qual, se não forem tratados ou se forem tratados de forma inadequada, ao serem lançados nos corpos receptores, podem ocasionar concentrações superiores àquelas recomendadas.

Quando esses eventos ocorrem, é preciso reparar as condições ambientais com rapidez, de modo adequado e integral e com a compatibilização de técnicas eficientes e economicamente viáveis (CARNEIRO; GARIGLIO, 2010).

É nesse cenário que as técnicas de biorremediação têm sido aplicadas com sucesso para descontaminação de solo, águas subterrâneas e superficiais, assim como para recuperação de ecossistemas (PRASAD, 2011), pois, além de apresentarem menores custos econômicos, podem resultar em menores danos para o ambiente quando comparadas à maioria das outras formas físicas e químicas de remediação (YANG et al., 2009).

De acordo com Yakubu (2007), o termo biorremediação é um processo biotecnológico no qual se utiliza o metabolismo de microrganismos para a degradação de poluentes, resultando na redução da sua concentração a níveis aceitáveis, transformando-os em compostos menos tóxicos.

Com relação à biodegradação do glifosato em meio aquoso, os estudos, além de serem escassos, foram realizados sob condições específicas - como utilização de bactérias isoladas e adaptadas (FU et al., 2017) ou substratos preparados a partir de produtos puros (HALLAS; ADAMS; HEITKAMP, 1992) — , de forma que há falta de informações, principalmente, sobre a biodegradação de compostos comerciais à base de glifosato.

De acordo com Obojska, Lejczak e Kubrak (1999) e Wang et al. (2015), a biodegradação de compostos orgânicos fosforados, como o glifosato, pode ocorrer de três formas: como fonte de fósforo em ambientes onde esse composto é limitado, por cometabolismo ou ambos.

De forma simplificada, na biorremediação cometabólica, a degradação do composto persistente é estimulada por um substrato primário, facilmente degradável, denominado de cosubstrato (MACEDO et al., 2015). Diferentes compostos podem ser utilizados como cosubstratos, entre eles estão o etanol, o acetato, a frutose, a glicose e outros.

A presença do cosubstrato pode influenciar o processo de degradação de um composto persistente de duas formas: primeiro, estimulando o crescimento celular e, assim, melhorando a transformação do composto persistente; segundo, durante a metabolização do substrato primário, pode ocorrer a indução de vias enzimáticas que poderão ser utilizadas também para a degradação do composto persistente (XIE et al., 2009).

Na literatura, é possível verificar a aplicação do cometabolismo para diferentes compostos, como fármacos (SATHYAMOORTHY; CHANDRAN; RAMSBURG, 2013), compostos fenólicos (WANG et al., 2015) e outros contaminantes orgânicos considerados de difícil degradação (TRAN et al., 2013; WANG; CHU, 2017), porém há falta de informação sobre esse tipo de metabolismo com relação à degradação do glifosato.

Dessa forma, levando-se em consideração que, em ambientes aquáticos, as bactérias estão expostas a diferentes fontes de carbono, mais ou menos degradáveis (HOREMANS et al., 2014), e as concentrações de fósforos são relativamente baixas, exceto em ambientes eutrofizados, acredita-se que a biorremediação do glifosato realizada por cometabolismo também possa estar presente.

Diante de tais observações, o presente trabalho avaliou a eficiência e a cinética da biodegradação aeróbia do glifosato (formulação comercial) na ausência e na presença de etanol como cosubstrato no processo, sob três condições de relação etanol:glifosato.

\section{MATERIAIS E MÉTODOS}

A pesquisa foi desenvolvida no Laboratório de Saneamento da Universidade Federal de Goiás, na Escola de Engenharia Civil e Ambiental. Foi utilizado reator de vidro, com capacidade volumétrica de $1 \mathrm{~L}$, operado em regime de batelada sequencial (RBS) e crescimento suspenso de biomassa. Foram mantidos ciclos de 24 horas, divididos em 5 minutos para a alimentação, 15 minutos para o descarte, 15 minutos de sedimentação e 23 horas e 25 minutos para o tratamento aeróbio.

$\mathrm{O}$ fornecimento de oxigênio foi realizado por meio de injeção de ar atmosférico utilizando um compressor de ar, comumente utilizado em aquários, modelo SC-7500, com vazão de $6 \mathrm{~L} \cdot \mathrm{min}^{-1}$, e uma pedra porosa de forma que, em todas as fases estudas, a concentração de oxigênio dissolvido se manteve próxima a $7 \mathrm{mg} \cdot \mathrm{L}^{-1}$.

O inóculo do reator foi lodo aeróbio proveniente do decantador secundário do sistema de lodos ativados utilizado para o tratamento de efluentes de uma indústria farmacêutica. A concentração de sólidos totais voláteis na partida do reator foi de 4,7 g. $\mathrm{L}^{-1}$. A biomassa foi mantida em suspensão utilizando um agitador magnético, e a temperatura média de operação foi de $26 \pm 2^{\circ} \mathrm{C}$.

O sistema foi operado por 120 dias, sem contar o período de 60 dias para adaptação do lodo aeróbio às condições anóxicas, e foram testadas quatro condições nutricionais distintas para glifosato e etanol, conforme apresentadas na Tabela 1 .

A água utilizada para preparar o afluente do reator foi a bruta do manancial João Leite. As coletas foram realizadas na Estação de Tratamento 
de Água (ETA) Jaime Câmara, da Saneago, localizada no município de Goiânia (GO). As caraterísticas físico-químicas da água utilizada durante o período de ensaio foram: alcalinidade $=50 \pm 10 \mathrm{mg} . \mathrm{L}^{-1}$; fósforo $=0,04 \pm$ $0,02 \mathrm{mg} . \mathrm{L}^{-1} ;$ nitrato e nitrogênio amoniacal não foram detectados; $\mathrm{DBO}_{5.20}$ $=3,5 \pm 1,2 \mathrm{mg} . \mathrm{L}^{-1}$; turbidez $=12 \pm 3,2 \mathrm{NTU}$; e pH = 7,2 $\pm 0,45$. Devido aos baixos valores de nutrientes na água utilizada para o preparo do substrato, foram adicionados $\mathrm{NH}_{4} \mathrm{Cl}\left(12 \mathrm{mg} \cdot \mathrm{L}^{-1}\right.$ de N-NH$\left.{ }_{4}^{+}\right)$e $\mathrm{K}_{2} \mathrm{HPO}_{4}$ (0,1 mg. $\mathrm{L}^{-1}$ de $\mathrm{P}-\mathrm{PO}_{4}^{3-}$ nas fases 1 e 2 e $1 \mathrm{mg} . \mathrm{L}^{-1}$ de $\mathrm{P}-\mathrm{PO}_{4}^{3-}$ nas demais). A concentração de nitrogênio baseou-se na utilizada por Massenssini et al. (2008), e a de fósforo iniciou-se com valores baixos (fase 1) devido ao fato de a biodegradação do glifosato poder ser favorecida em ambientes onde o fósforo se encontra limitado (CASTRO JR.; PERALBA; AYUB, 2007; HOVE-JENSEN; ZECHEL; JOCHIMSEN, 2014).

A fonte de glifosato foi produto comercial à base de sal de di-amônio de glifosato 445 g.L. $\mathrm{L}^{-1}$ (370 g.L $\mathrm{L}^{-1}$ equivalente de ácido). As concentrações utilizadas foram $5 \mathrm{mg} . \mathrm{L}^{-1}$ para o período de adaptação (resultados não apresentados) e, nas demais fases, os valores foram adotados em função da resposta do tratamento.

O etanol foi utilizado como cosubstrato, baseando-se em resultados satisfatórios obtidos por outros autores ao tratarem compostos de difícil degradação, como surfactante (MACEDO et al., 2015) e metil t-butil éter (ZHANG; CHEN; FANG, 2008).

A eficiência de remoção do glifosato foi calculada por meio da Equação 1:

$\mathrm{E}=\frac{\left(\mathrm{C}_{\mathrm{o}}-\mathrm{C}_{\mathrm{r}}\right)}{\mathrm{C}_{\mathrm{o}}}{ }^{\star} 100$

Em que:

$\mathrm{E}=$ eficiência de remoção (\%);

$\mathrm{C}_{0}=$ concentração inicial de glifosato $\left(\mathrm{mg} \cdot \mathrm{L}^{-1}\right)$;

$\mathrm{C}_{\mathrm{r}}=$ concentração final de glifosato no fim do ciclo $\left(\mathrm{mg} \cdot \mathrm{L}^{-1}\right)$.

No fim de cada fase, foi realizada análise de sólidos totais voláteis (STV) segundo método gravimétrico.

O monitoramento do sistema foi realizado duas vezes por semana por meio de medidas do pH e análises das concentrações de glifosato, fósforo,

Tabela1-Condições nutricionais utilizadas nos ensaios de biorremediação.

\begin{tabular}{l|c|c|c|c}
\multirow{2}{*}{} & $\begin{array}{c}\text { Fase 1 } \\
\text { 30 dias }\end{array}$ & $\begin{array}{c}\text { Fase 2 } \\
33 \text { dias }\end{array}$ & $\begin{array}{c}\text { Fase 3 } \\
33 \text { dias }\end{array}$ & $\begin{array}{c}\text { Fase 4 } \\
24 \text { dias }\end{array}$ \\
\cline { 2 - 5 } Glifosato & \multicolumn{4}{|c}{ Concentração (mg.L') } \\
\hline Etanol & 10 & 10 & 10 & 15 \\
\hline Relação etanol:glifosato & - & 78,5 & 274,8 & 274,8 \\
\hline DQO & $<100^{1}$ & $145 \pm 15$ & $421 \pm 35$ & $430 \pm 30$ \\
\hline
\end{tabular}

DQO: demanda química de oxigênio; 'concentração abaixo do limite de detecção do método (100 mg.L'1). demanda química de oxigênio (DQO) e oxigênio dissolvido (OD) no afluente e efluente do reator (resultados não apresentados) e, após constatado o equilíbrio dinâmico aparente, foram realizados os ensaios cinéticos mediante perfis temporais do decaimento da concentração de glifosato e fósforo. Os perfis foram realizados em duplica e em dias diferentes.

Os dados obtidos foram ajustados utilizando o software Origin ${ }^{\circledR}$, versão 9.0, seguindo o modelo de decaimento exponencial de pseudoprimeira ordem com residual utilizado por Mendonça (2002), que é apresentado na Equação 2:

$\mathrm{C}_{\mathrm{t}}=\mathrm{C}_{\mathrm{r}}+\left(\mathrm{C}_{\mathrm{o}}+\mathrm{C}_{\mathrm{r}}\right) \mathrm{e}^{-\mathrm{kt}}$

Em que:

$\mathrm{C}_{\mathrm{t}}=$ concentração residual de substrato no tempo $\left(\mathrm{mg} \cdot \mathrm{L}^{-1}\right)$;

$\mathrm{C}_{\mathrm{r}}=$ concentração residual de substrato $\left(\mathrm{mg} \cdot \mathrm{L}^{-1}\right)$;

$\mathrm{C}_{0}=$ concentração inicial de substrato $\left(\mathrm{mg} \cdot \mathrm{L}^{-1}\right)$;

$\mathrm{k}=$ constante cinética aparente de pseudoprimeira ordem $\left(\mathrm{min}^{-1}\right)$;

$\mathrm{t}=$ tempo $(\mathrm{min})$

Para avaliar a qualidade dos ajustes cinéticos, foram utilizados como critérios os valores dos coeficientes de correlação e o teste de $\chi^{2}$ reduzido $\left(\chi_{\text {red }}^{2}\right)$, que leva em consideração as respostas observadas experimentalmente e os valores preditos pelo modelo. Foi utilizada a tabela de probabilidade percentual Prob $\left(\widetilde{\mathrm{X}}^{2} \geq \widetilde{\mathrm{X}}_{0}^{2}\right)$, com intervalo de confiança $\mathrm{P}=95 \%$.

As análises de glifosato foram realizadas em triplicata, seguindo método proposto por Bhaskara e Nagaraja (2006). As demais análises seguiram métodos propostos por APHA (2012).

\section{RESULTADOS E DISCUSSÃO}

\section{Cinética de degradação do glifosato}

Na Figura 1, são apresentados os resultados da variação temporal da concentração de glifosato durante o período de ciclo para as quatro fases estudadas.

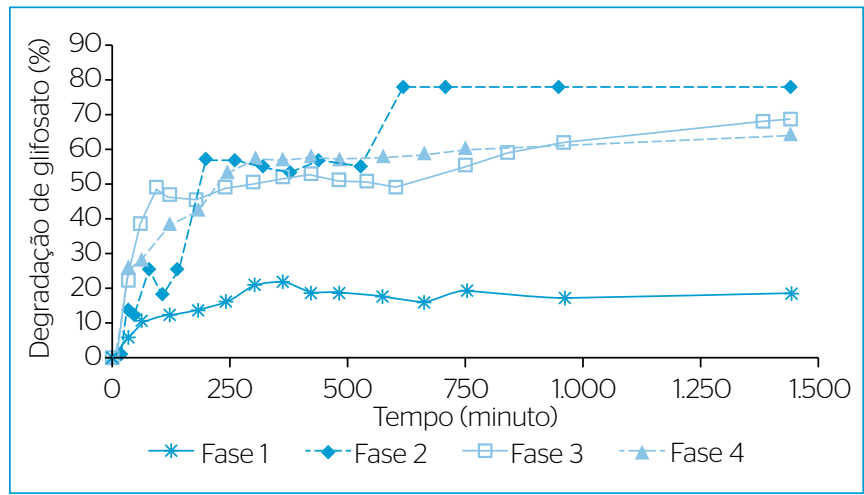

Figura 1 - Variação temporal da concentração de glifosato para as quatro fases estudadas. 
Os resultados obtidos e apresentados na Figura 1 permitem verificar, com exceção da fase 1, que a maior parte da remoção cerca de $50 \%$ - ocorreu nos primeiros 250 minutos. Esse tempo de degradação é menor que o tempo médio de 5 dias obtido por Castro Jr., Peralba e Ayub (2007) para degradar, em biorreatores aeróbios, $41 \%$ de glifosato com concentração inicial de $50 \mathrm{mg} \cdot \mathrm{L}^{-1}$ e o de 40 dias reportado por Wang et al. (2016) para mineralizar cerca de $50 \%$ de ${ }^{13} \mathrm{C}_{3}$-glifosato com concentração inicial de $3 \mathrm{mg} . \mathrm{L}^{-1}$ (equivalente a $50 \mathrm{mg} \cdot \mathrm{L}^{-1}$ de glifosato). Porém, cabe ressaltar que os referidos trabalhos utilizaram concentrações superiores ao do presente estudo, de forma que o glifosato pode ter atuado tanto como inibidor do crescimento microbiano quanto da degradação do substrato (NOUROUZI et al., 2012).

Com relação aos ajustes cinéticos, na Figura 2, são apresentados os perfis temporais para a degradação do glifosato obtidos nas fases de 1 a 4 .
É possível verificar, nos gráficos $2 \mathrm{~B}$ a 2D, apresentados na Figura 2, que o decaimento da concentração de glifosato em função do tempo apresentou dois comportamentos cinéticos (ver indicação), mais evidentes nas fases 2 (Figura 2B) e 3 (Figura 2C).

Na fase 2, nota-se, nos primeiros 200 minutos, remoção de $60 \%$ da concentração inicial de glifosato, seguida de um período de equilíbrio de, aproximadamente, 330 minutos antes de um segundo decaimento de $58 \%$ com relação à concentração de equilíbrio. $\mathrm{Na}$ fase 3 , a degradação inicial de glifosato foi de $48 \%$ nos primeiros 300 minutos, seguida de um período de equilíbrio de 450 minutos e um segundo decaimento de 12,8\% com relação à primeira concentração de equilíbrio. Já na fase 4 (Figura 2D), praticamente, não é possível detectar dois decaimentos cinéticos.

A presença de dois comportamentos cinéticos durante a degradação biológica do glifosato também foi observada por Wang et al. (2016). No experimento, entre o $10^{\circ}$ e o $40^{\circ}$ dia do tratamento de $50 \mathrm{mgL}^{-1}$

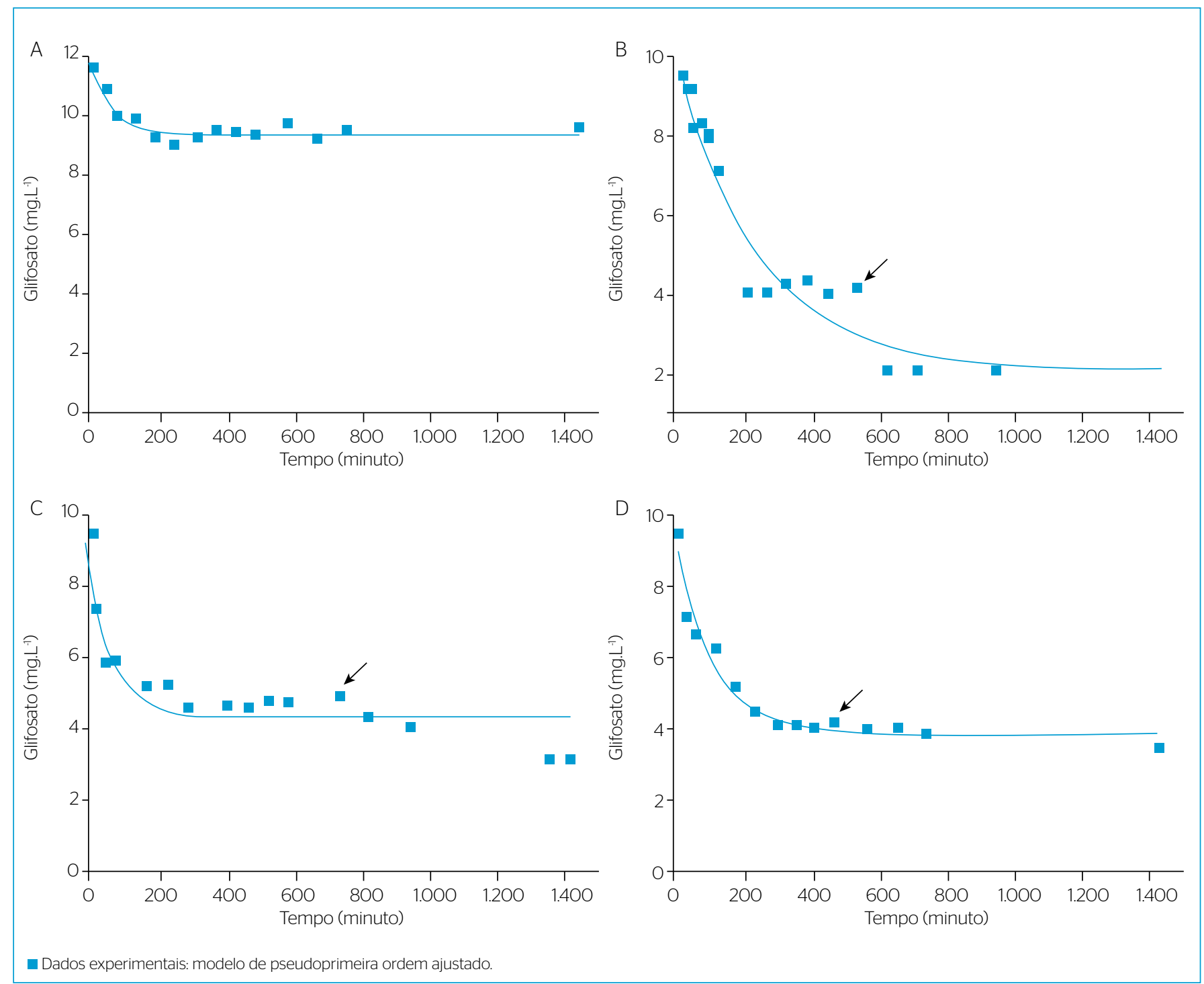

Figura 2 - Perfis temporais do decaimento da concentração de glifosato. (A) Fase 1 (sem etanol); (B) fase 2 (etanol:glifosato = 7,8:1); (C) fase 3 (etanol:glifosato = 27,5:1); (D) fase 4 (etanol:glifosato =18,3:1). 
de glifosato ( ${ }^{13} \mathrm{C}_{3}$-glifosato), os autores relataram remoção de $40 \%$ da concentração inicial de glifosato, que se manteve constante por 20 dias antes de aumentar para cerca de $60 \%$ até o fim do tratamento, porém o fato não foi abordado pelos autores.

No presente trabalho, a presença de dois comportamentos cinéticos pode estar relacionada com a rota metabólica utilizada para a degradação do glifosato e a presença do cosubstrato. De acordo com Zhan et al. (2018), as principais rotas de degradação do glifosato são: a da sarcosina, que produz sarcosina, glicina e fósforo; e a do AMPA, caracterizada pela formação e pelo acúmulo do ácido aminometilfosfônico (AMPA), que, em uma segunda etapa, pode ser degradado fornecendo fósforo inorgânico para o meio.

No sistema em estudo, acredita-se que houve a prevalência da rota metabólica via AMPA, conforme esquema apresentado na Figura 3.

Dessa forma, baseando-se no mecanismo de degradação do glifosato via AMPA, acredita-se que o rápido decaimento da concentração de glifosato, observado no início do ciclo de tratamento (Figura 2), pode estar associado ao metabolismo de bactérias que utilizam o glioxilato como substrato energético no ciclo de Krebs, acumulando AMPA (SVIRIDOV et al., 2015). Nessa etapa, a presença de fósforo inorgânico não afeta o metabolismo dos organismos (BORGGAARD; GIMSING, 2008). Acredita-se até mesmo que esse composto tenha sido utilizado como fonte de fósforo inorgânico pelos organismos, visto seu rápido decaimento durante o ciclo de tratamento, conforme apresentado na Figura 4.

Durante a fase 2 , as concentrações de fósforo se mantiveram abaixo do limite de detecção do método, não sendo possível acompanhar seu decaimento. Porém, ao analisar o consumo desse composto nas fases 3 e 4, pode-se verificar que a estabilização no decaimento da concentração de glifosato encontra-se próxima ao período no qual as concentrações de fósforo alcançaram valores inferiores a cerca de $70 \%$ da sua concentração inicial. Esses valores baixos podem ter inibido o metabolismo de degradação.
No entanto, em situações nas quais a concentração de fósforo se torna limitante, ocorre a ativação da enzima responsável pela clivagem das ligações C-P da molécula do AMPA (WANG et al., 2016), e este passa a ser mineralizado a fosfato $\left(\mathrm{PO}_{3}^{4-}\right)$ (McAULIFFE; HALLAS; KULPA, 1990), o qual poderia ser utilizado na segunda etapa de decaimento do glifosato observada.

$\mathrm{Na}$ fase 1, não foi possível observar esse comportamento, pois ele pode ser dependente da presença de fontes de carbono alternativas como cosubstrato, conforme observaram Balthazor e Hallas (1986) ao estudarem a degradação do glifosato utilizando organismos da espécie Flavobacterium sp. em um sistema aeróbio.

Na Tabela 2, são apresentados os dados de eficiência de remoção do glifosato e das constantes cinéticas aparentes obtidas para as diferentes condições da relação etanol:glifosato estudadas.

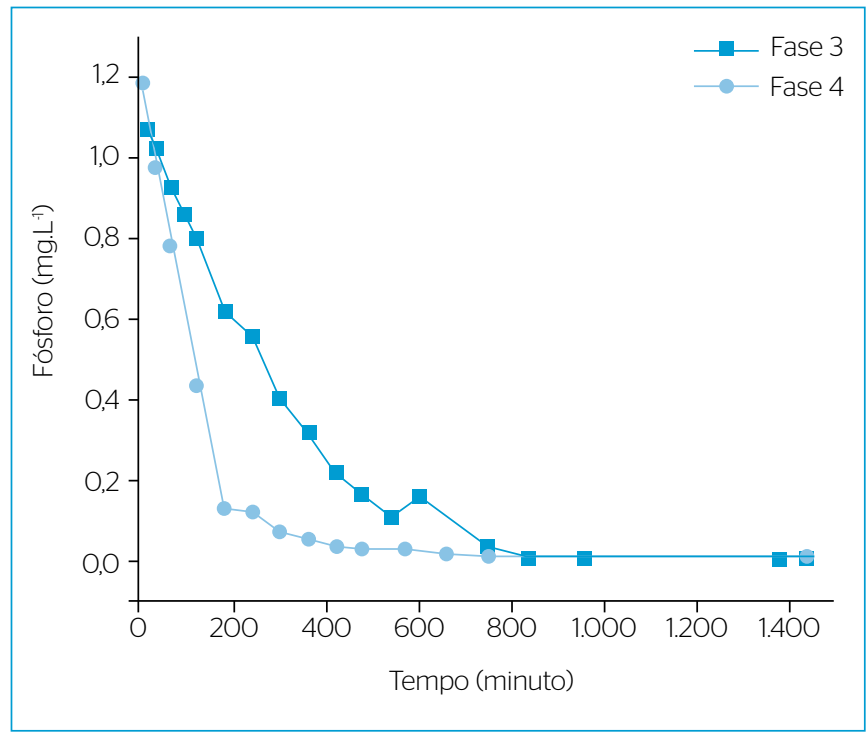

Figura 4 - Decaimento da concentração de fósforo inorgânico durante as fases 3 e 4 .

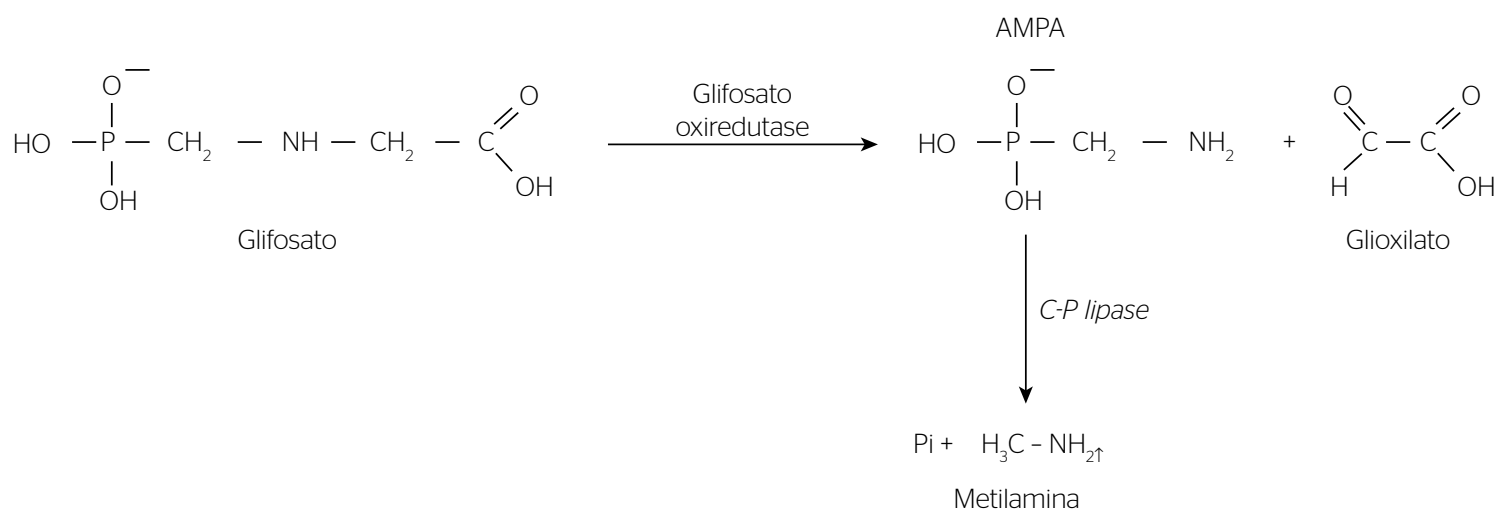

Fonte: adaptado de Sviridov et al. (2015)

Figura 3 - Rota de degradação biológica do glifosato via formação de AMPA. 
Pode-se verificar que a degradação aeróbia do glifosato foi descrita de forma satisfatória pelo modelo de pseudoprimeira ordem com residual do herbicida, vistos os altos valores do coeficiente de correlação $\left(\mathrm{R}^{2}\right)$ e os baixos valores de $\chi_{\text {red }}^{2}\left(\chi_{\text {red }}^{2}<1\right)$. Para todas as condições, a $\operatorname{Prob}\left(\widetilde{\mathrm{X}}^{2} \geq \widetilde{\mathrm{X}}_{0}^{2}\right)$ com intervalo de confiança $\mathrm{P}=95 \%$ foi superior a $96 \%$.

Com relação à influência do cosubstrato nas velocidades de reação, pode-se verificar que o aumento na relação etanol:glifosato com exceção da fase que operou sem etanol - aumentou os valores das constantes cinéticas aparentes.

Xie et al. (2009) também obtiveram correlação positiva entre a relação succinato de sódio:malation (cosubstrato:composto alvo) e taxa de degradação do malation, fato este associado ao aumento no número de organismos degradadores devido à maior concentração de substrato de crescimento. Porém, quando a relação passou de 12,86 para $25,72 \mathrm{~g} . \mathrm{L}^{-1}$, foi observada diminuição na constante cinética aparente de 3,5837 para 2,8995 mg. $\mathrm{L}^{-1} \cdot \mathrm{h}^{-1}$, a qual pode ser explicada, neste caso, devido ao provável uso preferencial do succinato, que já não se encontrava sob condição limitante (HARDER; DIJKHUIZEN, 1982).

No presente estudo, foram observadas situações semelhantes. Na fase sem etanol, obteve-se constante cinética aparente de 0,01086. $\min ^{-1}$ e, quando foi adicionado etanol na proporção de 7,8:1, esse valor diminuiu para $0,00385 \cdot \mathrm{min}^{-1}$. Acredita-se que a inserção do etanol, em um primeiro momento, tenha ocasionado o uso preferencial deste em detrimento do glifosato.

Nas demais fases, quando a relação etanol:glifosato foi maior (18,3:1 e 27,5:1), observaram-se aumentos nos valores das constantes cinéticas aparentes, provavelmente, devido ao aumento no número de organismos responsáveis pela degradação do glifosato, uma vez que os valores de sólidos totais voláteis passaram de 128 (fim da fase 1) para $302 \mathrm{mg} . \mathrm{L}^{-1}$ (fim da fase 4).

\section{Eficiência de degradação do glifosato}

Na Figura 5, são apresentados os resultados de remoção de glifosato acumulado em função do tempo de ciclo para as condições estudadas.

Ao analisar os resultados apresentados na Figura 5, pode-se verificar que a presença do etanol como cosubstrato teve influência significativa na remoção do glifosato, que passou de $18,06 \pm 1,14 \%$, quando

Tabela 2 - Resultados dos ajustes cinéticos obtidos para as diferentes condições de relação etanol:glifosato estudadas.

\begin{tabular}{l|c|c|c|c|c} 
Fase & Relação $E / G^{1}$ & $E(\%)^{2}$ & $k\left(m^{1}\right)^{3}$ & $X^{2}{ }_{\text {red }}^{4}$ & $R^{25}$ \\
\hline 1 & Sem etanol & 18,06 & 0,01086 & 0,04472 & 0,90793 \\
\hline 2 & $7,8: 1$ & 77,98 & 0,00385 & 0,51286 & 0,9369 \\
\hline 3 & $27,5: 1$ & 66,12 & 0,01746 & 0,42299 & 0,84146 \\
\hline 4 & $18,3: 1$ & 58,75 & 0,00857 & 0,30286 & 0,95687 \\
\hline
\end{tabular}

'Relação etanol:glifosato; 'eficiência de remoção do glifosato; ${ }^{3}$ constante cinética aparente de pseudoprimeira ordem; ${ }^{4} \chi$ reduzido; ${ }^{5}$ coeficiente de correlação. o sistema operou sem etanol, para 77,98 $\pm 0,17 \%$ tendo etanol na relação 7,38:1, o que equivale a um aumento na eficiência de remoção de $1,89 \pm 0,11 \mathrm{mg} . \mathrm{L}^{-1}$ para $7,33 \pm 0,013 \mathrm{mg} \cdot \mathrm{L}^{-1}$ durante o período de tratamento. Boopathy (2016) verificou aumento de 36\% na remoção do herbicida atrazina quando utilizou melaço como cosubstrato em sistema anóxico. Marinho et al. (2017) também obtiveram aumento de $32 \%$ na degradação aeróbia da atrazina por fungos Aspergillus $s p$. ao utilizarem 3 g.L $L^{-1}$ de glicose como cosubstrato.

Hallas, Adams e Hheitkamp (1992), que utilizaram um sistema de lodos ativados para o tratamento de glifosato, verificaram que a eficiência do processo estava relacionada tanto à presença de nitrogênio quanto à fonte de carbono adicional, neste caso, o extrato de levedura.

O aumento observado na eficiência da fase 2 em comparação com a 1 poderia ser explicado se levado em consideração que a biodegradação de pesticidas é resultante, frequentemente, da atividade de consórcios bacterianos com interações sinergéticas entre os organismos membros (HOREMANS et al., 2014). No presente estudo, a adição da fonte de carbono de fácil degradação, como o etanol, pode ter auxiliado tanto na composição da diversidade microbiana, favorecendo os grupos responsáveis pela degradação do glifosato, quanto na quantidade de espécies envolvidas no processo (MACEDO et al., 2015; ZHANG; LO, 2015).

A hipótese do crescimento de organismos capazes de degradarem o glifosato fundamenta-se na variação da concentração de sólidos suspensos voláteis verificada no fim das fases 1 e 2 , a qual aumentou de 128 para $257 \mathrm{mg} . \mathrm{L}^{-1}$, respectivamente. Comportamento semelhante também foi verificado por Xie et al. (2009), os quais observaram aumento na absorbância

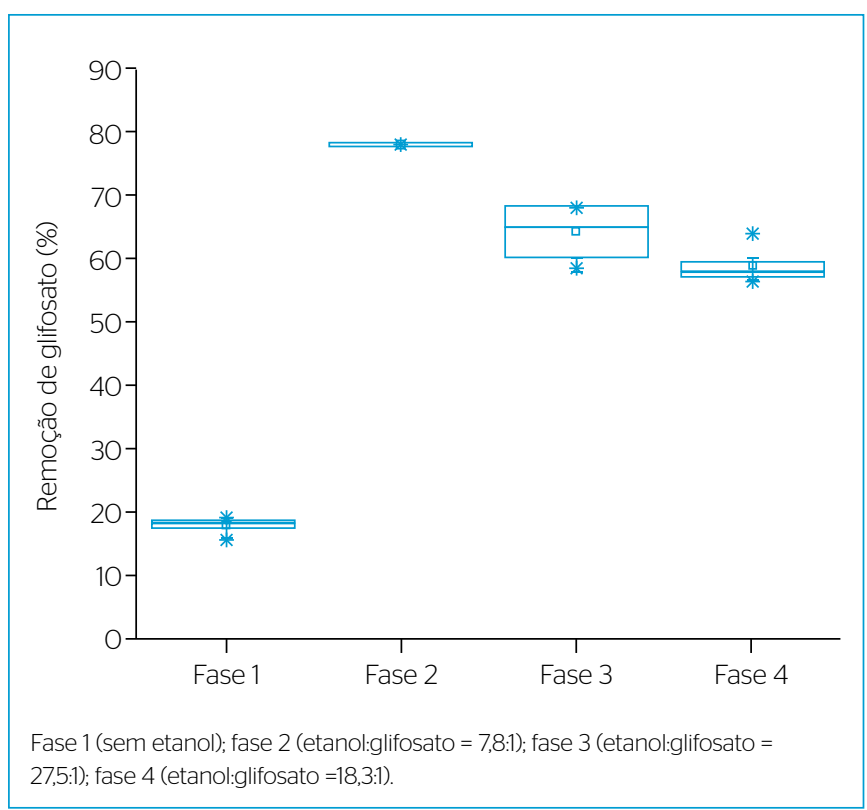

Figura 5 - Glifosato removido no fim do ciclo de operação para as quatro fases estudadas. 
da densidade de bactérias $\left(\mathrm{OD}_{600}\right)$ de 0,605 para 1,813 ao utilizarem acetato de sódio como cosubstrato para a degradação do malation.

Já o aumento da remoção do glifosato devido a possíveis alterações na composição da diversidade microbiana se sustenta em dados semelhantes obtidos por Macedo et al. (2015), que associaram as maiores eficiências na remoção do linear alquilbenzeno sulfonato (LAS) com o aumento no percentual de organismos responsáveis pela degradação desse composto em detrimento de outras espécies quando utilizaram o etanol como cosubstrato.

Embora tenha sido possível observar aumento na degradação do glifosato com adição de 78,5 mg.. $\mathrm{L}^{-1}$ de etanol, o mesmo não ocorreu na fase 3 , quando foi utilizada concentração de $274,8 \mathrm{mg} . \mathrm{L}^{-1}$, perfazendo relação etanol:glifosato aproximada de 27,5 . Nessa fase, o que se verificou foi diminuição na eficiência de remoção para $68,1 \pm 3,6 \%$, equivalente à degradação de $6,87 \pm 0,30 \mathrm{mg} \cdot \mathrm{L}^{-1}$. Situação semelhante foi relatada por Marinho et al. (2017), que, ao aumentarem a concentração de glicose de 3 para 5 g.L $L^{-1}$, constataram diminuição na eficiência de remoção da atrazina de $72 \pm 2 \%$ para $62 \pm 2 \%$. Ainda, Horemans et al. (2014) verificaram diminuição de $83 \pm 2 \%$ para $51 \pm 1 \%$ na eficiência de remoção do herbicida Linurom quando o cosubstrato (succionato de sódio) aumentou de $5 \mathrm{mg} . \mathrm{L}^{-1}$ para $20 \mathrm{mg} . \mathrm{L}^{-1}$.

A interferência negativa do excesso do cosubstrato no processo pode ser explicada tanto por mudanças na composição da diversidade microbiana quanto por alterações nas rotas catabólicas (BREUGELMANS et al., 2010) devido ao uso preferencial de substratos específicos como fonte de carbono principal para economia energética (MARINHO et al., 2017).

Os resultados obtidos, assim como nos experimentos de Breugelmans et al. (2010) e Horemans et al. (2014), demonstram que o efeito na eficiência de degradação de um composto alvo está associado à concentração do cosubstrato utilizado, e esta deve ser avaliada para cada caso específico.

$\mathrm{Na}$ fase 4, quando a concentração de glifosato foi aumentada para 15 mg. $\mathrm{L}^{-1}$ a fim de se obter relação etanol:glifosato igual a 18,3:1 (relação intermediária entre as fases 2 e 3 ), a remoção do glifosato foi, aproximadamente, $4 \%$ menor que a obtida na fase 3 , embora a quantidade de glifosato removida tenha aumentado de $6,87 \pm 0,30 \mathrm{mg} \cdot \mathrm{L}^{-1}$ para $9,66 \pm$
0,41 mg. $\mathrm{L}^{-1}$. Nessa fase, acredita-se que a principal influência na degradação do glifosato tenha sido a alteração na relação substrato/biomassa.

Wang et al. (2016), ao avaliarem a eficiência de remoção do glifosato em um sistema sedimento-água, associaram a eficiência de tratamento à relação substrato:biomassa. Os pesquisadores usaram duas concentrações iniciais de glifosato, 3 e $50 \mathrm{mg} . \mathrm{L}^{-1}$, e verificaram que a taxa de degradação para o experimento com menor concentração foi duas vezes maior quando comparado com o de $50 \mathrm{mg}$. $\mathrm{L}^{-1}$, fato este em função da elevada concentração de substrato frente à baixa concentração de organismos responsáveis pela degradação do composto.

Em comparação, nas fases 3 e 4 do presente estudo, a concentração de sólidos voláteis totais no sistema foi de 264 e $302 \mathrm{mg} . \mathrm{L}^{-1}$, respectivamente, de tal forma que a relação substrato:biomassa (glifosato:sólidos suspensos voláteis - SSV) em ambas as fases foi de 0,03 (fase 3) e 0,05 (fase 4).

\section{CONCLUSÃO}

O presente trabalho avaliou a eficiência e cinética da degradação de formulação comercial a base de glifosato em meio aquoso via processo aeróbio, utilizando etanol como cosubstrato.

Os resultados permitem concluir que a remoção do glifosato pode ser beneficiada com o uso do etanol como cosubstrato no processo, porém a relação etanol:glifosato ideal deve ser avaliada para cada situação em função da concentração do segundo. Para o presente trabalho, essa relação mais adequada foi de 7,8:1 para concentração inicial de glifosato de $10 \mathrm{mg} \mathrm{L}^{-1}$, que permitiu remoção de 77,98 \pm 0,17\%.

Com relação à cinética de degradação, o processo foi adequadamente descrito pelo modelo de pseudoprimeira ordem com residual. A presença de dois comportamentos cinéticos e o consumo de fósforo inorgânico adicionado ao sistema sustentam a hipótese de que a rota de degradação do glifosato tenha ocorrido via formação de AMPA. $\mathrm{O}$ aumento na relação etanol:glifosato favorece a cinética de degradação, desde que os organismos presentes no sistema já estejam adaptados à utilização do etanol como cosubstrato, caso contrário este pode ser utilizado, preferencialmente, em detrimento do uso do glifosato

\section{REFERÊNCIAS}

AMARANTE JUNIOR, O.P.; SANTOS, T.C.R.; BRITO, N.M.; RIBEIRO, M.L. (2002) Glifosato: propriedades, toxicidade, usos e legislação. Química Nova, v. 25, n. 4, p. 589-593. http://dx.doi.org/10.1590/ S0100-40422002000400014

AMERICAN PUBLIC HEALTH ASSOCIATION (APHA). (2012) Standard Methods for the Examination of Water and Wastewater. 22. ed. Washington, D.C.: Pharmabooks.
BALTHAZOR, T.M.; HALLAS, L.E. (1986) Glyphosate-Degrading Microorganisms from Industrial Activated Sludge. Applied and Environmental Microbiology, v. 51, n. 2, p. 432-434.

BATTAGLIN, W.A.; MEYER, M.T.; KUIVILA, K.M; DIETZE, J.E. (2O14) Glyphosate and its degradation product AMPA occur frequently and Widely in U.S. soils, surface water, groundwater, and precipitation. Journal of the American Water Resources Association, v. 50, n. 2, p. 275-290. https://doi.org/10.1111/jawr.12159 
BHASKARA, B.L.; NAGARAJA, P. (2006) Direct sensitive spectrophotometric determination of glyphosate by using ninhydrin as a chromogenic reagent in formulations and environmental water samples. Helvetica Chimica Acta, v. 89, n. 11, p. 2686-2693. https://doi.org/10.1002/hlca.200690240

BONIFÁCIO, A.F.; CAZENAVE, J.; BACCHETTA, C.; BALLESTEROS, M.L.; BISTONI, M. A.; AMÉ, M.V.; BERTRAND, L.; HUED, A.C. (2O16) Alterations in the general condition, biochemical parameters and locomotor activity in Cnesterodon decemmaculatus exposed to commercial formulations of chlorpyrifos, glyphosate and their mixtures. Ecological Indicators, v. 67, p. 88-97. https://doi.org/10.1016/j.ecolind.2016.02.011

BOOPATHY, R. (2016) Anaerobic degradation of atrazine. International Biodeterioration \& Biodegradation, v. 119, p. 626-630. https://doi.org/10.1016/j.ibiod.2016.10.002

BORGGAARD, O.K.; GIMSING, A.L.D. (2008) Fate of glyphosate in soil and the possibility of leaching to ground and surface waters: a review. Pest Management Science, v. 64, n. 4, p. 441-456.

BRASIL. (2005) Conselho Nacional do Meio Ambiente. Resolução no 357, de 17 de março de 2005. Conselho Nacional do Meio Ambiente.

BREUGELMANS, P.; HOREMANS, B.; HOFKENS, J.; SPRINGAEL, D. (2010) Response to mixed substrate feeds of the structure and activity of a linuron-degrading triple-species biofilm. Research in Microbiology, v. 161, n. 8, p. 660-666. https://doi.org/10.1016/j. resmic.2010.06.006

CARNEIRO, D. de A.; GARIGLIO, L.P. (2010) A biorremediação como ferramenta para a descontaminação de ambientes terrestres e aquáticos. Revista Tecer, v. 3, n. 4, p. 82-95. http://doi. org/10.15601/1983-7631/rt.v3n4p82-95

CASTRO JR., J.V.; PERALBA, M.C.R.; AYUB, M.A.Z. (2007) Biodegradation of the herbicide glyphosate by filamentous fungi in platform shaker and batch bioreactor. Journal of Environmental Science and Health Part B, v. 42, n. 8, p. 883-886. https://doi. org/10.1080/03601230701623290

FU, G.; CHEN, Y.; LI, R.; YUAN, X.; LIU, C.; LI, B.; WAN, Y. (2017) Pathway and rate-limiting step of glyphosate degradation by Aspergillus oryzae A-FO2. Preparative Biochemistry \& Biotechnology, v. 47, n. 8, p. 782-788. https://doi.org/10.1080/10826068.2017.1342260

HALLAS, L.E.; ADAMS, W.J.; HEITKAMP, M.A. (1992) Glyphosate degradation by immobilized bacteria: field studies with industrial wastewater effluent. Applied and Environmental Microbiology, v. 58, n. 4, p. 1215-1219.

HARDER, W.; DIJKHUIZEN, L. (1982) Strategies of mixed substrate utilization in microorganisms. Philosophical Transactions of the Royal Society of London, Series B, v. 297, n. 1088, p. 459-480. https:// doi.org/10.1098/rstb.1982.0055

HOREMANS, B.; VANDERMAESEN, J.; BREUGELMANS, P.; HOFKENS, J.; SMOLDERS, E.; SPRINGAEL, D. (2014) The quantity and quality of dissolved organic matter as supplementary carbon source impacts the pesticide-degrading activity of a triple-species bacterial biofilm. Applied Microbiology and Biotechnology, v. 98, n. 2. p. 931-943. https://doi.org/10.1007/s00253-013-4928-4
HOVE-JENSEN, B.; ZECHEL, D.L.; JOCHIMSEN, B. (2014) Utilization of glyphosate as phosphate source: Biochemistry and genetics of bacterial carbon-phosphorus Iyase. Microbiology and Molecular Biology Reviews, v. 78, n. 1, p. 176-197. https://doi.org/10.1128/ MMBR.00040-13

MACEDO, T.; OKADA, D.; DELFORNO, T.; BRAGA, J.; SILVA, E.; VARESCHE, M. (2O15) The comparative advantages of ethanol and sucrose as co-substrates in the degradation of an anionic surfactant: microbial community selection. Bioprocess and Biosystems Engineering, v. 38, n. 10, p. 1835-1844. https://doi. org/10.1007/s00449-015-1424-5

MARINHO, G.; BARBOSA, B.C.A.; RODRIGUES, K.; AQUINO, M.; PEREIRA, L. (2017) Potential of the filamentous fungus Aspergillus niger AN 400 to degrade Atrazine in wastewaters. Biocatalysis and Agricultural Biotechnology, v. 9, p. 162-167. https://doi.org/10.1016/j. bcab.2016.12.013

MCAULIFFE, K.S.; HALLAS, L.E.; KULPA, C.F. (1990) Glyphosate degradation by Agrobacterium radiobacterisolated from activated sludge. Journal of Industrial Microbiology, v. 6, n. 3, p. 219-221.

MENDONÇA, L.C. (2002) Microbiologia e cinética de sistemas de lodos ativados como pós-tratamento de efluente de reator anaeróbio de leito expandido. 219f. Tese (Doutorado) - Escola de Engenharia de São Carlos, Universidade de São Paulo, São Carlos, SP. Disponível em: <http://www.teses.usp.br/teses/ disponiveis/18/18138/tde-07042003-143948/pt-br.php>. Acesso em: 27 jan. 2017.

MUÑOZ, L.M.H.; VELASQUEZ, T.M.T.; BAUTISTA, M. H. B. (2O15) Evaluación de la toxicidad de dos agroquímicos, Roundup ${ }^{\circledR}$ activo y Cosmo-flux ${ }^{\circledR} 411 f$, en renacuajos de anuros colombianos. Acta Biológica Colombiana, v. 2, p. 153-161.

NOUROUZI, M.M.; CHUAH, T.G.; CHOONG, T.S.Y; RABIEI, F. (2O12) Modeling biodegradation and kinetics of glyphosate by artificial neural network. Journal of Environmental Science and Health, Part B, v. 47, n. 5, p. 455-465. https://doi.org/10.1080/03601234.2012.663603

OBOJSKA, A.; LEJCZAK, B.; KUBRAK, M. (1999) Degradation of phosphonates by streptomycete isolates. Applied Microbiology and Biotechnology, v. 51, n. 6, p. 872-876.

PRASAD, M.N.V. (2O11) A state-of-the-art report on bioremediation, its applications to contaminated sites in India. Índia: Ministry of Environment \& Forests. 90 p. Disponível em: <http://docplayer. net/28104918-A-state-of-the-art-report-on-bioremediation-itsapplications-to-contaminated-sites-in-india.html>. Acesso em: 20 nov. 2016

SATHYAMOORTHY, S.; CHANDRAN, K.; RAMSBURG, C.A. (2013) Biodegradation and cometabolic modeling of selected beta blockers during ammonia oxidation. Environmental Science \& Technology, v. 47, n. 22, p. 12835-12843. https://doi.org/10.1021/ es402878e

SUN, K.; LIU, W.; LIU, L.; WANG, N.; DUAN, S. (2013) Ecological risks assessment of organophosphorus pesticides on bloom of Microcystis wesenbergii. International Biodeterioration \& Biodegradation, v. 77, p. 98-105. 
SVIRIDOV, A.; SHUSHKOVA, T.; ERMAKOVA, I.; IVANOVA, E.; EPIKTETOV, D.; LEONTIEVSKY, A. (2O15) Microbial degradation of glyphosate herbicides (Review) Applied Biochemistry and Microbiology, v. 51, n. 2, p. 188-195. https://doi.org/10.1134/ S0003683815020209

TRAN, N.H.; URASE, T.; NGO, H.H.; HU, J.; ONG, S.L. (2O13) Insight into metabolic and cometabolic activities of autotrophic and heterotrophic microorganisms in the biodegradation of emerging trace organic contaminants. Bioresource Technology, v. 146, p. 721 731. https://doi.org/10.1016/j.biortech.2013.07.083

UNITED STATES ENVIRONMENTAL PROTECTION AGENCY (USEPA). (2017) Pesticides Industry Sales and Usage 2008-2012 Estimates. USEPA. Disponível em: <https://www.epa.gov/sites/ production/files/2017-01/documents/pesticides-industry-salesusage-2016_O.pdf>. Acesso em: 20 nov. 2016.

WANG, B.; CHU, K. (2017) Cometabolic biodegradation of 1,2,3-trichloropropane by propane-oxidizing bacteria. Chemosphere, v. 168, p. 1494-1497. https://doi.org/10.1016/j. chemosphere.2016.12.007

WANG, Q.; LI, Y.; LI, J.; WANG, Y.; WANG, C.;WANG, P.(2015)Experimental and kinetic study on the cometabolic biodegradation of phenol and 4-chlorophenol by psychrotrophic Pseudomonas putida LY1. Environmental Science and Pollution Research International, v. 22, n. 1, p. 565-573. https://doi.org/10.1007/s11356-014-3374-x

WANG, S.; SEIWERT, B.; KÄSTNER, M.; MILTNER, A.; SCHÄFFER, A.; REEMTSMA, T.; YANG, Q.; NOWAK, K.M. (2016) (Bio)degradation of glyphosate in water-sediment microcosms - A stable isotope co-labeling approach. Water Research, v. 99, p. 91-100. https://doi. org/10.1016/j.watres.2016.04.041
WILLIAMS, G.M.; KROES, R.; MUNRO, I.C. (2000) Safety evaluation and risk assessment of the herbicide roundup and its active ingredient, glyphosate, for humans. Regulatory Toxicology and Pharmacology, v. 31, p. 117-165. https://doi.org/10.1006/rtph.1999.1371

XIE, M.; LIU, Z:; XU, Y. (2O10) Removal of glyphosate in neutralization liquor from the glycine-dimethylphosphit process by nanofiltration. Journal of Hazardous Materials, v. 181, n. 1-3, p. 975-980. https://doi. org/10.1016/j.jhazmat.2010.05.109

XIE, S.; LIU, J.; LI, L.; QIAO, C. (2009) Biodegradation of malathion by Acinetobacter johnsonii MA19 andoptimization of cometabolism substrates. Journal of Environmental Sciences, v. 21, n. 1, p. 76-82. https://doi.org/10.1016/S1001-0742(09)60014-O

YAKUBU, M.B. (2007) Biological approach to oil spills remediation in the soil. African Journal of Biotechnology, Nigéria, v. 6, n. 24, p. 2735-2739. http://dx.doi.org/10.5897/AJB2007.000-2437

YANG, S.; JIN, H.-J.; WEI, Z.; HE, R.-X.; JI, Y.-J.; LI, X.-M.;YUM S.-P. (2009) Bioremediation of oil spills in cold environments: a review. Pedosphere, v. 19, п. 3, p. 371-381. https://doi.org/10.1016/S1002O160(09)60128-4

ZHANG, L.L.; CHEN, J.M.; FANG, F. (2008) Biodegradation of methyl t-butyl ether by aerobic granules under a cosubstrate condition. Applied Microbiology and Biotechnology, v. 78, n. 3, p. 543-550. https://doi.org/10.1007/s00253-007-1321-1

ZHANG, Z.; LO, I. (2015) Biostimulation of petroleum-hydrocarboncontaminated marine sediment with co-substrate: involved metabolic process and microbial community. Applied Microbiology and Biotechnology, v. 99, n. 13, p. 5683-5696. https://doi.org/10.1007/ s00253-015-6420-9 